\title{
Simulation Study and Influencing Factors Analysis of Mini - car
}

\section{Platform Tilting Test}

\author{
Changye Liu ${ }^{1,2, a}$, Yimin Mo ${ }^{2, b}$, Yong Wei ${ }^{1, c}$, Zhigui Lin ${ }^{1, d}$, \\ Yongbin Liang $^{2,}$, Feng Wang ${ }^{1,2, f}$ \\ 1.Technical Development Centre,SAIC-GM-WulingAutomobile CO., Ltd,Liuzhou, China; \\ 2. Wuhan University of Technology, Wuhan, China; \\ aChangye.Liu@sgmw.com.cn, ${ }^{\mathrm{b}}$ moyimin@whut.edu.cn, ${ }^{\mathrm{c}}$ Yong.Wei@sgmw.com.cn, \\ d'Zhigui.Lin@sgmw.com.cn, ${ }^{\text {[502637785@qq.com , }}$ 'Feng.wang@sgmw.com.cn
}

Key words: Dolly Rollover Test; Multi-body Model; Collision Parameters; Occupant Injury Abstract: A multi-body model based on dolly rollover test for the minivan is introduced in detail and validated by comparing time relative error of the key motions in the absence of dummy. It is shown that the simulation model is accurate enough for later research. The influence law between rollover characteristics and initial collision parameters including the distance between dolly and ground, the height of baffle, the initial angel and the velocity of the vehicle is researched. The results indicate that occupant comprehensive injuries to head and neck have a positive correlation to falling height, baffle height and tilt angel, and have a negative correlation to initial velocity.

\section{Introduction}

At present, there are no mandatory regulations for vehicle rollover safety characteristics other than FMVSS 208 regulations which involve vehicle rollover characteristics test method. The rollover characteristics test method in FMVSS 208 regulations come from SAE J2114 dolly rollover test[1].In research work that has been carried out, the main basis are quasi static standards of FMVSS 216 and ECE R66, which is mainly targeted at vehicle strength of top structure. Vehicle dynamic rollover characteristics has not been studied in-depth[2].Therefore, research work of automobile dynamic rollover has a important economic significance and social significance.

\section{Building and validation of the simulation model}

\section{MB model}

In the process of building MB model, considering the actual situation, the MB model is built on the basis of existing finite-element(FE) model. Vehicle model can be obtained by copy elements and nodes information of key components in FE model to the MB software-MADYMO[3].

\section{Analysis of the simulation and experiment}

\section{Comparison of results}

(1) Comparison of Vehicle Motion State

The key motion states and relative errors are shown in Table 1. Figure 1 shows the simulation and experimental key motion state comparison chart. 
Table 1. Results contrast of Simulation and Test

\begin{tabular}{cccc}
\hline Motion state & Moment of simulation ( $\mathrm{ms}$ ) & Moment of test $(\mathrm{ms})$ & Relative error (\%) \\
\hline $1 / 4$ circle & 422 & 410 & 2.93 \\
$1 / 2$ circle & 1618 & 1600 & 1.13 \\
$3 / 4$ circle & 2166 & 2090 & 3.64 \\
1 circle & 2610 & 2680 & 2.61 \\
\hline & &
\end{tabular}

Fig.1 Comparison of Simulation and Experimental Key Motion States

(2) Comparison of vehicle

In the test, the acceleration sensor was installed at the bottom of the B-pillar to measure the acceleration of the vehicle during the test. The main direction of movement of the vehicle is $\mathrm{Y}$, so only the Y-direction acceleration is compared, the test and simulation curve shown in Figure 2.

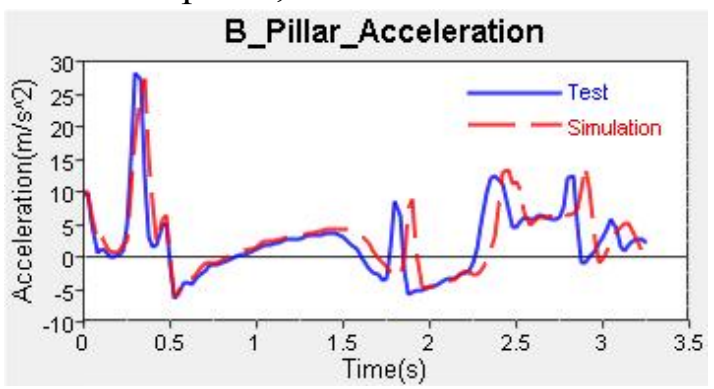

Fig. 2 Comparison of the Acceleration of the Lower of the B - Pillar

Compared with the acceleration curve, the simulation results show that the test is in good agreement with the trend and peak of the simulation curve, and the simulation time point is slightly delayed but the error requirement is satisfied. The model has sufficient accuracy.

\section{Research for the influence law of the collision parameters}

\section{Determination of influence factors}

The initial height of the test dolly to the ground, the initial height of the dolly baffle, the initial tilt angle of the vehicle and the initial velocity of the vehicle can be changed in dolly rollover test, so these four initial collision parameters are chosen as influence factors. Base on the scope of the dolly and according to the uniform test design principle, these four values are required to have $\pm 5 \%$ and $\pm 10 \%$ deviation with the fundamental value $[4,5]$. The simulation parameters selection results shown in Table 2.

Table 2. The Values of Simulation Parameters

\begin{tabular}{cccc}
\hline Falling Height $(\mathrm{mm})$ & Height of Baffle $(\mathrm{mm})$ & Tilt Angle $\left.^{(}\right)$ & Initial Velocity $(\mathrm{Km} / \mathrm{h})$ \\
\hline $205.7 / 217.2$ & 101.6 & 23 & 48 \\
228.6 & $91.4 / 96.5$ & 23 & 48 \\
228.6 & 101.6 & $20.7 / 21.9$ & 48 \\
228.6 & 101.6 & 23 & $43.2 / 45.6$ \\
\hline
\end{tabular}




\section{Analysis of Results}

Making reference to evaluation criterion in frontal barrier crash test, lateral moving barrier crash test and whiplash test, dummy HIC36, neck maximum load in the $\mathrm{Z}$ direction and chest deflection, a total of three occupant injury criterions are chosen as evaluation standard for rollover characteristics[6,7]. In order to research the influence law more intuitive, divide each injury value acquired in different simulations by them acquired in fundamental values case.

Head acceleration curve, injury value HIC36, as well as corresponding posture of the vehicle and the dummy is shown in Figure 3. Neck load in the $\mathrm{Z}$ direction, as well as the posture of the vehicle and the dummy at the moment of peak injury is shown in Figure 4. Chest deflection curve, as well as the posture of the vehicle and the dummy at the time of peak deflection is shown in Figure 5.

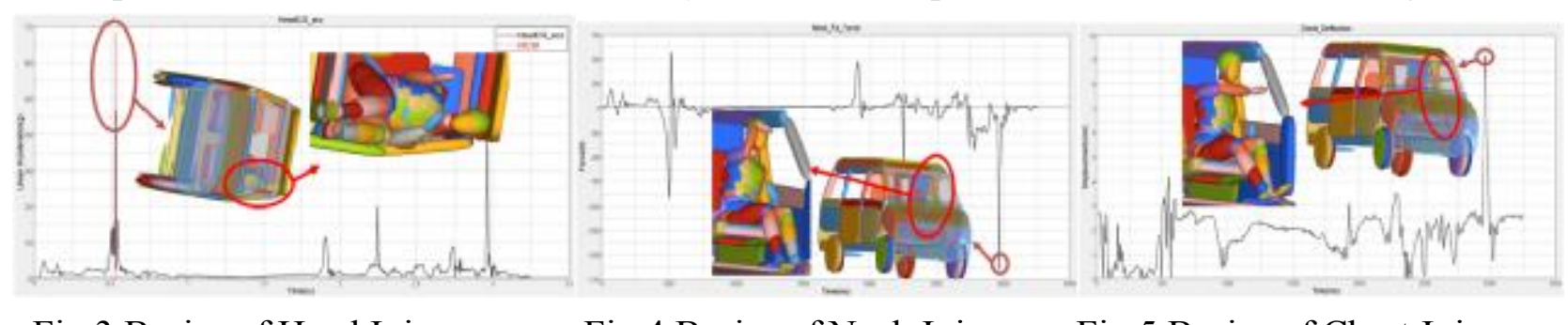

Fig.3 Basics of Head Injury

Fig.4 Basics of Neck Injury

Fig.5 Basics of Chest Injury

\section{Falling Height}

The dynamic response results of the dummy in different falling height are listed in Table 3. At the same time, the influencing trend between dummy injury and falling height is shown in figure 6 .

Table 3. Simulation Results in Different Falling Height

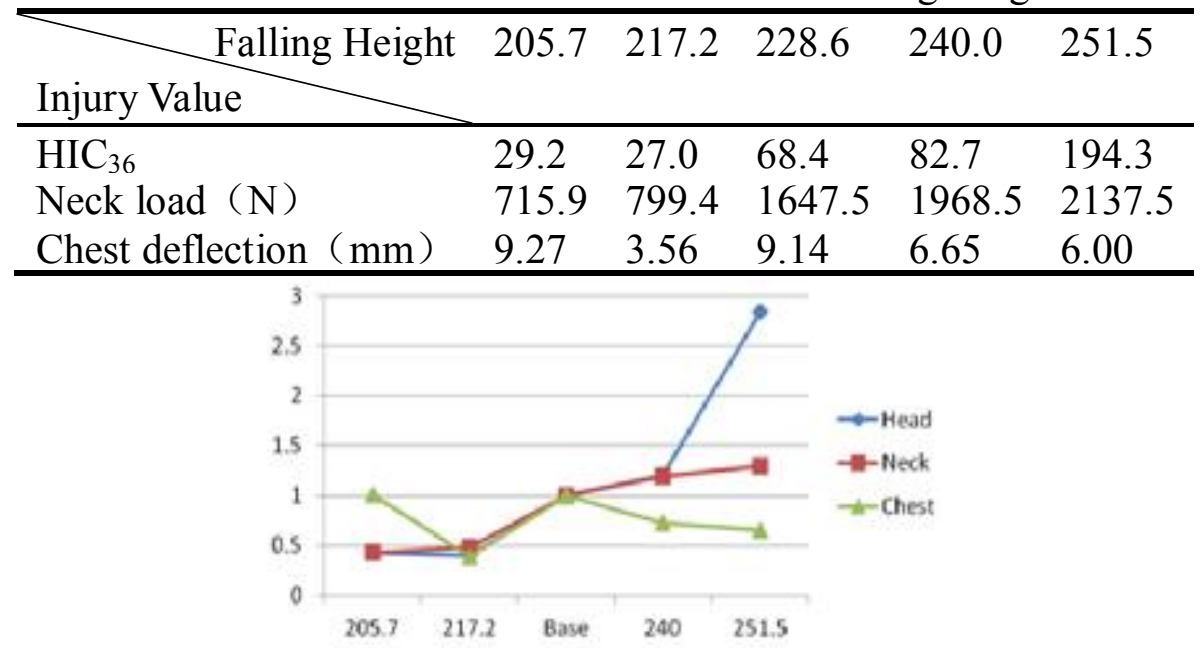

Fig. 6 The Effect of Drop Height on Dummy Injury

It can be found that dummy HIC36 occurs at the moment of the vehicle rolling one circle in the falling height of $240.0 \mathrm{~mm}$, furthermore, in other falling height HIC36 all occurs at the moment of the vehicle rolling $1 / 4$ circle. The posture of dummy head during HIC36-Curve period in the height of $240.0 \mathrm{~mm}$ and the others are shown in Figure 7(a) and Figure 7(b). With the increase of falling height, relative collision velocity of dummy head and the vehicle parts becomes increasingly higher, which leads to a worse state of the collision, so the value of HIC36 becomes larger and the injury degree of head becomes worse. 


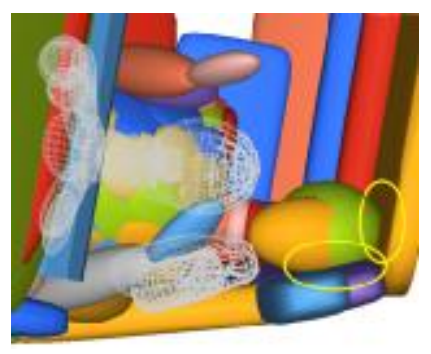

(a)

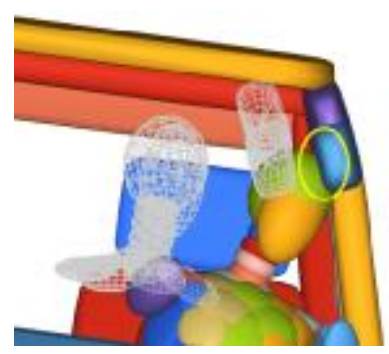

(b)

Fig.7 The Time Period of HIC36-Curve for the Head State

When the falling height is low, the vehicle only rolls $1 / 4$ circle, so the neck injury of dummy is small. Neck maximum load occurs for the reason of press between the head and the roof at the moment of the vehicle rolling $1 / 4$ circle, and the posture of dummy in this case is shown in figure 8(a). In the rest of falling height, cycles of the rollover are all one, and neck maximum load occurs at the moment of the vehicle rolling 1 circle, which is also the moment of the maximum press occurs between the head and the top beam of A pillar, and the dummy posture in this case is shown in figure 8(b). With the increase of falling height, the velocity of the vehicle on its first contact moment with ground is bigger, which also has an influence on the velocity of rolling 1 circle moment. Therefore, with the increase of falling height, the velocity of dummy head and neck becomes larger. Which causes a larger neck load, so the neck injury increases[8].

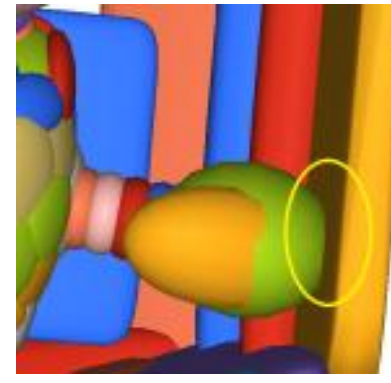

(a)

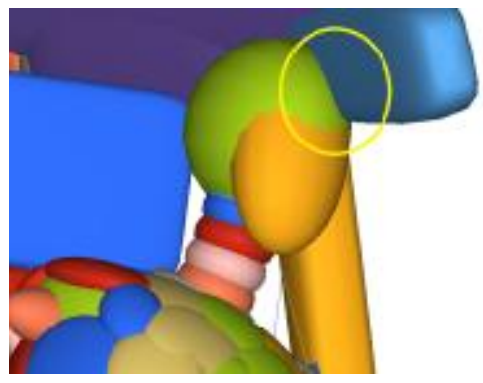

(b)

Fig. 8 The State of the Neck Z to the Maximum Load

\section{Baffle Height}

Different heights of the baffle are set for simulation analysis, and the values of dummy injury are shown in Table4, furthermore, the influencing trend of baffle height on dummy injury is shown in Figure 12.

Table 4.Simulation Results in Different Baffle Height Cases

\begin{tabular}{|c|c|c|c|c|c|c|}
\hline Injury Value & le Height & 91.4 & 96.5 & 101.6 & 106.7 & 111.8 \\
\hline $\begin{array}{l}\mathrm{HIC}_{36} \\
\text { Neck Load (N) } \\
\text { Chest Deflection }\end{array}$ & $(\mathrm{mm})$ & $\begin{array}{l}25.6 \\
921.8 \\
3.80\end{array}$ & $\begin{array}{l}17.9 \\
621.0 \\
7.53 \\
\end{array}$ & $\begin{array}{l}68.4 \\
1647.5 \\
9.14\end{array}$ & $\begin{array}{l}306.6 \\
1309.1 \\
11.17 \\
\end{array}$ & $\begin{array}{l}369.3 \\
1733.6 \\
10.24 \\
\end{array}$ \\
\hline $\begin{array}{l}6 \\
5 \\
4 \\
3 \\
2 \\
1 \\
0\end{array}$ & $\underset{91.4 \quad 96.5}{2}$ & Base & 106.7 & & & \\
\hline
\end{tabular}

Fig.9 Influence of Baffle Height on Dummy Injury 
The dummy HIC36occurs at the moment of the vehicle rolling $1 / 4$ circle in all cases. As the increase of the baffle height, the contact location of the tires and the baffle becomes higher, which causes a larger angular velocity of rotation and a larger relative velocity of the head to the roof, so there is an increasing trend of the head injury on the whole. When the baffle height is $96.5 \mathrm{~mm}$, the head injury is smaller than it in which case the baffle height is $91.4 \mathrm{~mm}$. The reason for this is that the vehicle along the $\mathrm{Y}$ axis movement velocity decrease degree is greater than it in former case, so the head injury has a temporary decrease[9].

When the baffle height is less than the fundamental value, the vehicle only rolls $1 / 4$ circle, for the reason that the vehicle rotation speed is small, and neck maximum load in the $\mathrm{Z}$ direction occurs at the moment of the vehicle rolling 1/4 circle. The neck maximum load all occurs at the moment of the vehicle rolling 1 circle in the rest cases. The baffle height have an influence on the movement velocity in the $\mathrm{X}$ axis and rotation speed in the $\mathrm{Y}$ axis for the vehicle.

\section{Tilt Angle}

Table 5 shows the simulation results under different initial tilt angle. The influencing trend of the angle on dummy injury is shown in Figure 10.

Table 5.Simulation Results in Different Tilt Angle Cases

\begin{tabular}{|c|c|c|c|c|c|}
\hline $\begin{array}{ll}\text { Injury Value } & \text { Tilt Angle } \\
\end{array}$ & 20.7 & 21.9 & 23 & 24.2 & 25.3 \\
\hline $\mathrm{HIC}_{36}$ & 30.4 & 42.5 & 68.4 & 76.4 & 300.2 \\
\hline Neck Load（N） & 639.7 & 723.8 & 1647.5 & 1689.0 & 1770.1 \\
\hline Chest Deflection $(\mathrm{mm})$ & 6.57 & 8.34 & 9.14 & 8.25 & 9.21 \\
\hline
\end{tabular}

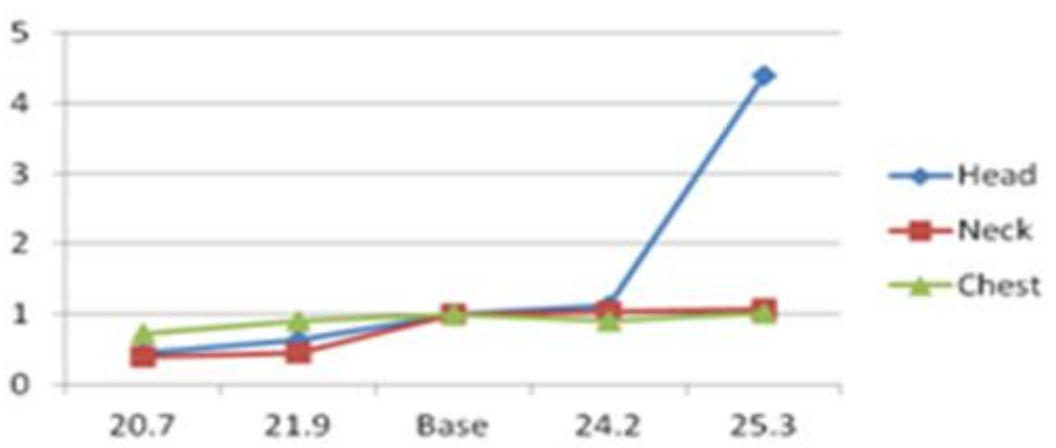

Fig.10 Influence of Tilt Angle on Dummy Injury

Dummy head injury is also caused by the collision of dummy head and the vehicle parts. After vehicle initial tilt angle increases, dummy initial swing angle becomes larger, so the dummy will get the dangerous position at an earlier time, and the collision degree of the head and vehicle parts becomes worse, which cause a more serious head injury[10].

At the moment of the first contact in this case, before dummy head contact roof or top beam, the vehicle has moved to the next state, so the maximum load of neck is pull. Dummy posture on the moment of the maximum pull is shown in Figure 11. As tilt angle increases, the vehicle rolls 1 circle, and the maximum load is caused by the collision of dummy head and A-pillar top beam at the moment of the vehicle rolling 1 circle, which lead to a stress for dummy neck. With the increase of initial tilt angle, the head and the neck get dangerous posture more easily, so the neck maximum load increases with the increase of tilt angle. 


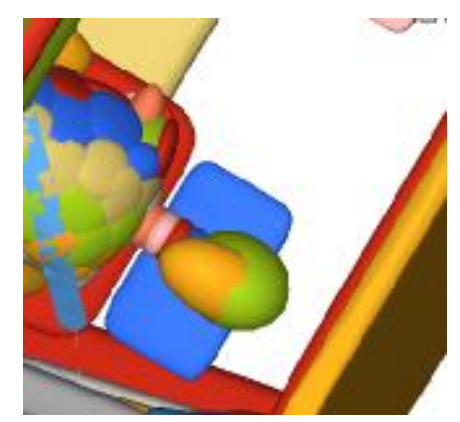

Fig. 11 The State of Maximum Tension on The Dummy Neck

Chest deflection is around $10 \mathrm{~mm}$, and there is an increasing trend of it on the whole. it can be found that the maximum deflection occurs at the moment of the first contact between the vehicle and the ground when the vehicle only rolls $1 / 4$ circle. And the posture of dummy in this case is shown in Figure 12(a). In other cases, the maximum deflection all occurs at the moment of the vehicle rolling 1 circle. Posture of dummy is shown in Figure 12(b). With the increase of tilt angle, the initial state of dummy becomes more dangerous, and the injury caused by the inertia in the process of rolling becomes worse, so chest deflection becomes larger[11,12].

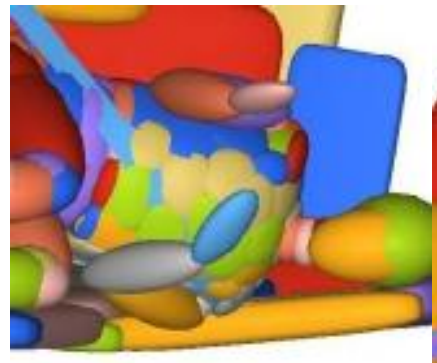

(a)

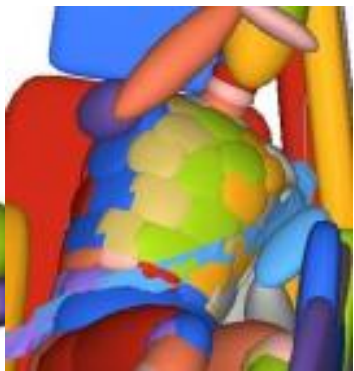

(b)

\section{Initial Velocity}

Fig.12 The State of Maximum Compression of Dummy Chest

With the change of the vehicle initial velocity, the simulation results as shown in Figure 6 can be got. The influencing trend between dummy injury and initial velocity is shown in Figure 13.

Table 6.Simulation results in different initial velocity cases

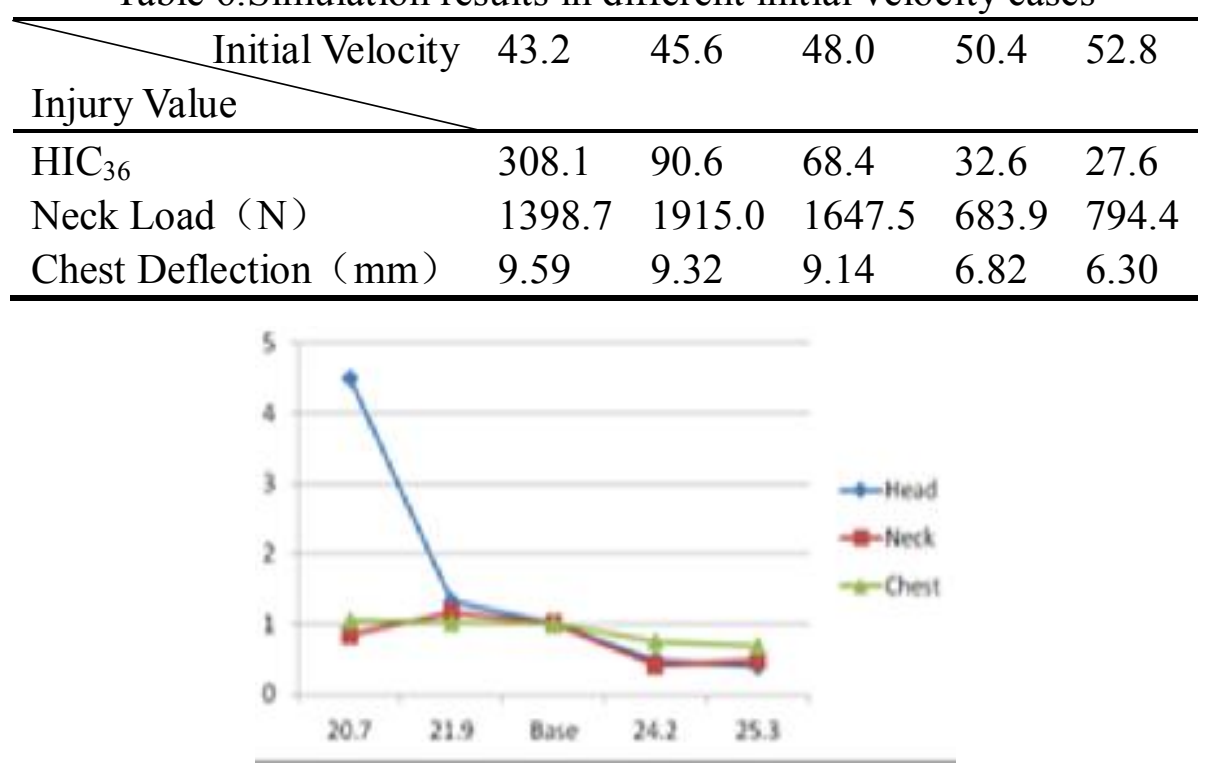

Fig. 13 the Influence of Initial Velocity on Dummy Injury

Through the simulation animation, it can be found that the vehicle only rolls $1 / 4$ circle when its velocity increase to $50.4 \mathrm{Km} / \mathrm{h}$. When initial velocity increases, free fall time before the vehicle 
collision contact with the ground is shorten, and the rotation speed at the moment of the contact decreases, which causes a less rolling circle, so the main movement type is relative sliding between the vehicle and the ground. With the increase of initial velocity, the collision time reduces, and the dummy will move to next state before it reached dangerous state for the reason of inertia, so its entire posture change is small. Therefore, dummy injury shows a decreasing trend.

\section{Conclusion}

By choosing vehicle falling height, dolly baffle height, vehicle tilt angle and initial velocity these four initial rollover collision parameters as influence factors, the clear influence relationship of initial parameters on dummy head and neck injury is acquired. Except that dummy head injury has a negative influence relationship with initial velocity, it has a positive influence relationship with falling height, baffle height and tilt angle. HIC36occurs at the moment of the vehicle first contact with the ground and the moment of the vehicle rolling 1 circle. Furthermore, vehicle velocity and motion posture at these two moments have a great influence on dummy head injury during the rolling collision. Neck injury has a positive influence relationship with falling height and tilt angle, and it has a negative relationship with initial velocity, but there has no obvious relationship be found between neck injury and baffle height. Neck maximum load in the $\mathrm{Z}$ direction occurs around the same time with head maximum injury. It is almost all caused by large neck stress, which occurs at the moment of collision between dummy head and vehicle parts. Dummy chest deflection varies in a small range, which is around $10 \mathrm{~mm}$. Although the moment of chest deflection peak has a certain law, the influence law between the deflection and collision parameters is not obvious. Taken together, except that dummy comprehensive injury is negatively related to initial velocity, it is positively related to falling height, baffle height and tilt angle.

\section{Reference}

[1] NHTSA, Department of Transportation, Federal Motor Vehicle Safety Standards (FMVSS) No. 208, Available at www.nhtsa.dot.gov.

[2] S.B. Albrodt, F. Tahan, and K. Digges, Evaluation of Different Roof Strength Methods in Quasi-Static and Dynamic Rollover Tests Using Finite Element Analysis of a 2003 Ford Explorer Model, in SAE 2014 World Congress \& Exhibition, 2014.

[3] C.C. Chou, and F. Wu, Development of MADYMO-based model for simulation of laboratory rollover test modes, 2005.

[4] D.P. Parent, J. Kerrigan, and J. Crandall, Comprehensive Computational Rollover Sensitivity Study Part 2: Influence of Vehicle, Crash, and Occupant Parameters on Head, Neck, and Thorax Response, Sae Technical Papers (2011).

[5] L. Yan, L. Cao, C. Kan, and P. Mohan, Comparison of vehicle kinematics and occupant responses between Jordan rollover system and an over-the-road rollover, International Journal of Crashworthiness 17 (2012), pp. 173-194.

[6] C. Jiang, C.E. Neal-Sturgess, and Y. Hu, Kinematics simulation and head injury analysis for rollovers using MADYMO, International Journal of Crashworthiness 15 (2010), pp. 505-515.

[7] D. Marjoux, D. Baumgartner, C. Deck, and R. Willinger, Head injury prediction capability of the HIC, HIP, SIMon and ULP criteria, Accident Analysis \& Prevention 40 (2008), pp. $1135-48$.

[8] G.A. Mattos, A.S. Mcintosh, R.H. Grzebieta, N. Yoganandan, and F.A. Pintar, Sensitivity of Head and Cervical Spine Injury Measures to Impact Factors 
[9] M.D. Freeman, K. Dobbertin, S.S. Kohles, L. Uhrenholt, and A. Eriksson, Serious Head and Neck Injury as a Predictor of Occupant Position in Fatal Rollover Crashe, Forensic Science International 222 (2012), pp. 228-33.

[10]K.M. Dobbertin, M.D. Freeman, W.E. Lambert, M.R. Lasarev, and S.S. Kohles, The relationship between vehicle roof crush and head, neck and spine injury in rollover crashes, Accident; analysis and prevention 58C (2013), pp. 46-52.

[11]K. Digges, A. Eigen, F. Tahan, and R. Grzebieta, Factors That Influence Chest Injuries in Rollovers, Traffic Injury Prevention 15 suppl 1 (2014), pp. S42-S48.

[12]TNO, MADYMO 7.4 User's Manual, TNO, Delft, The Netherlands, 2012. 